\title{
DOI: http://dx.doi.org/10.33846/sfl1414
}

Hubungan antara Self Efficacy dan Self Care Behavior pada Lansia dengan Hipertensi

Wimar Anugrah Romadhon

Fakultas Keperawatan, Universitas Airlangga; wimar.anugrah.romadhon-2018@fkp.unair.ac.id Joni Haryanto

Fakultas Keperawatan, Universitas Airlangga; joni.h.unair@gmail.com (koresponden)

Makhfudli

Fakultas Keperawatan, Universitas Airlangga; ievut_rz@yahoo.com

Setho Hadisuyatmana

Fakultas Keperawatan, Universitas Airlangga; setho.h@fkp.unair.ac.id

\begin{abstract}
Background: The incidence of hypertension in the elderly continues to increase every year and the problems that often occur in elderly hypertension are non-compliance with therapy or treatment, lifestyle changes, self care behavior that is less than optimal and the complications due to hypertension. This is influenced by beliefs (selfefficacy) that the elderly have to change their behavior, which is self care behavior which is not good. Purpose: to observe the relationship between self efficacy and self care behavior in the elderly with hypertension. Method: This study used a descriptive correlation design with a cross sectional approach. Overall, the samples obtained were 252 elderly with hypertension in the Surabaya Public Health Center area through cluster random sampling. Data were analyzed using the Spearman Rank test. Results: The elderly with hypertension have a self efficacy of $40.9 \%$ in the low category and $59.1 \%$ in the good category and have a self care behavior of $31.7 \%$ in the less category, $39.3 \%$ in category enough, $29 \%$ in the good category. This study shows a significant relationship between self efficacy and self care behavior with a value of $p=0,000<0.05$ and a coefficient correlation is 0,443 . Conclusion: there is a significant relationship between self efficacy and self care behavior in hypertensive elderly and the better self efficacy in elderly with hypertension, it tends to increase self care behavior. Recommendation: Nurse must be know that self-efficacy is the most important prerequisite for behavior change in elderly hypertension to provide self-confidence for elderly people doing self care behavior.
\end{abstract}

Keywords: self efficacy; self care behavior; elderly hypertension

\section{ABSTRAK}

Latar belakang: Kejadian hipertensi pada lansia terus meningkat tiap tahunnya dan masalah yang sering terjadi pada lansia hipertensi adalah ketidakpatuhan terhadap terapi atau pengobatan, merubah gaya hidup, perilaku perawatan diri yang kurang optimal dan adanya komplikasi akibat hipertensi. Hal ini dipengaruhi oleh keyakinan (efikasi diri) yang dimiliki lansia untuk merubah perilakunya yaitu perilaku perawatan diri yang kurang baik. Tujuan: untuk adalah mengetahui hubungan antara self efficacy dan self care behavior pada lansia dengan hipertensi. Metode: Penelitian ini menggunakan desain deskriptif korelasional dengan pendekatan cross sectional. Secara keseluruhan, sampel yang didapat sebanyak 252 lansia dengan hipertensi di wilayah puskesmas Surabaya melalui cluster random sampling. Data di analisis menggunakan uji Spearman Rank. Hasil: lansia dengan hipertensi memiliki self efficacy sebesar 40,9\% dalam kategori rendah dan 59,1\% dalam kategori baik serta memiliki self care behavior sebesar 31,7\% dalam kategori kurang, 39,3\% dalam kategori cukup, 29\% dalam kategori baik. Penelitian ini menunjukkan adanya hubungan yang signifikan antara self efficacy dan self care behavior dengan nilai $\mathrm{p}=0,000<0,05$ dan koefisien korelasi dengan nilai positif yaitu 0,443 . Simpulan: adanya hubungan yang signifikan antara self efficacy dengan self care behavior pada lansia hipertensi dan semakin baik self efficacy lansia dengan hipertensi maka cenderung dapat meningkatkan self care behavior nya. Saran: Perawat harus memahami bahwa self efficacy menjadi prasyarat terpenting untuk perubahan perilaku pada lansia hipertensi untuk memberikan kepercayaan diri lansia melakukan aktivitas perawatan diri.

Kata kunci: efikasi diri; perilaku perawatan diri; lansia hipertensi

\section{PENDAHULUAN}

Hal penting yang perlu diperhatikan oleh lansia dengan hipertensi adalah self care behaviour nya yang meliputi penggunaan obat-obatan, diet rendah garam, aktifitas fisik, merokok, manajemen berat badan dan konsumsi kopi ${ }^{(1,2)}$. Beberapa lansia dengan hipertensi cenderung tidak melakukan perawatan diri yang baik terbukti pada studi pendahuluan yang dilakukan di salah satu puskesmas di Surabaya yaitu dari 28 lansia hipertensi yang menunjukkan self care behaviour baik ada 43\%, cukup 28\%, dan kurang 29\%. Masalah utama manajemen hipertensi pada lansia adalah sikap lansia terhadap penyakitnya yang cenderung tidak patuh dalam melakukan perawatan diri. Hal ini disebabkan karena lansia memiliki konsep dan keyakinan yang berbeda seperti lansia yang mendapatkan pengetahuan tentang manajemen penyakit tidak selalu menerapkan perubahan perilaku yang diinginkan $^{(3)}$. Sebuah riset di Cina menyebutkan bahwa lansia dengan hipertensi yang tidak mampu melakukan perawatan diri secara mandiri cenderung mengalami peningkatan tekanan darah ${ }^{(4)}$. Kurangnya perhatian terhadap perilaku perawatan mandiri pada lansia dengan hipertensi merupakan penyebab utama kegagalan pada lansia 
untuk meningkatkan kualitas hidupnya ${ }^{(5)}$. Hubungan self efficacy dengan peningkatan self care behavior pada lansia hipertensi di Surabaya masih perlu untuk diteliti.

Menurut data Riskesdas Provinsi Jawa Timur proporsi penyakit hipertensi mencapai 1,34 juta atau sekitar 26,2\% dari total lansia di Jawa Timur. Proporsi penyakit hipertensi tertinggi terdapat pada kelompok usia $\geq 75$ tahun yaitu 62,4\% atau 838.693 lansia. Kota Surabaya mempunyai jumlah penduduk lansia terbesar ketiga di Jawa Timur sebanyak 219.056 jiwa $^{(6)}$. Dinas Kesehatan Kota Surabaya pada tahun 2014 mencatat hipertensi pada lansia sebanyak $19,56 \%$ atau sekitar 42.847 lansia menderita hipertensi.

Self efficacy merupakan kepercayaan seseorang dalam menentukan bagaimana orang merasakan, memikirkan, menggerakkan dan bertindak $^{(7)}$. Self efficacy juga merupakan keyakinan bahwa seseorang mempunyai kemampuan untuk melakukan kegiatan tertentu. Persepsi self-efficacy telah diketahui mempengaruhi keputusan tentang perilaku apa yang diambil. Self efficacy yang kuat akan tercipta pula kemampuan self care behavior yang tinggi. Individu dengan self efficacy tinggi memiliki keyakinan dalam kemampuan mereka untuk menerapkan perilaku tertentu ${ }^{(8)}$.

Peneliti melihat bahwa sebagian besar lansia yang mengalami hipertensi di wilayah kerja Puskesmas Surabaya kurang memperhatikan dan kurang memahami bagaimana seharusnya perawatan diri pada keadaan hipertensi. Penulis tertarik untuk mengobservasi dan melakukan penelitian dengan judul "Hubungan Self Efficacy dan Self care Behavior pada Lansia dengan Hipertensi". Tujuan dari penelitian ini adalah mengetahui hubungan self efficacy dengan self care behavior lansia dengan hipertensi di wilayah kerja Puskesmas Surabaya.

\section{METODE}

Penelitian ini menggunakan deskriptif korelasional dengan pendeketan cross-sectional yang bertujuan untuk mengungkapkan hubungan antara variabel self efficacy dan variabel self care behavior pada lansia hipertensi. Besar sampel dalam penelitian ini adalah semua lansia yang menderita hipertensi dengan jumlah 252 lansia dan Besaran sampel pada masing-masing Puskesmas yang merepresentasikan 5 wilayah secara proporsional dihitung dengan menggunakan teknik cluster random sampling. Penelitian ini dilakukan di Puskesmas Balongsari, Ketabang, Kenjeran, Keputih, dan Jemursari. Waktu penelitian dilaksanakan pada bulan Agustus sampai Desember 2019. Data primer diperoleh dengan teknik pengumpulan data melalui wawancara dan menggunakan lembar observasi yang disusun oleh peneliti. Pada penelitian ini, pengumpulan data untuk variabel bebas self efficacy dan variabel terikat self-care behavior dilakukan dengan cara membagikan kuesioner kepada subjek penelitian. Pengukuran tingkat self-efficacy pada penelitian ini menggunakan kuesioner Self Efficacy to Manage Hypertension dengan skala data ordinal dan kriteria hasil $\geq 28=$ baik, $^{2}<28=$ rendah $^{(9)}$. Kuisioner Self care behavior menggunakan H-Scale (Hypertension Self Care Activity Level Effects) dengan skala ordinal dan kriteria hasil 141-198=baik, 140-85=cukup, 84-28=kurang ${ }^{(2)}$, Analisis data yang digunakan untuk mengetahui ada tidaknya hubungan antara self-efficacy dengan self-care behavior pada lansia yang menderita hipertensi dengan uji korelasi Spearman Rank.

\section{HASIL}

Penelitian ini melibatkan 252 lansia dengan hipertensi dan bersedia menjadi responden. Hasil penelitian ini menyajikan tentang karakteristik responden, self-efficacy lansia hipertensi, self-care behavior lansia hipertensi, dan hubungan keduanya.

Dalam penelitian ini, klasifikasi karakteristik lansia dikelompokkan berdasarkan umur, jenis kelamin, IMT (Indeks Massa Tubuh), pendidikan, dan sosioekonomi. Distribusi dari karakteristik responden disajikan pada tabel 1.

Tabel 1. Distribusi karakteristik responden di wilayah kerja Puskesmas Surabaya

\begin{tabular}{|c|c|c|c|}
\hline Indikator & Kategori & Frequency & Percent \\
\hline \multirow{4}{*}{ Umur } & $60-74$ Tahun & 235 & 93,3 \\
\cline { 2 - 4 } & $75-90$ Tahun & 17 & 6,7 \\
\cline { 2 - 4 } & $>90$ Tahun & 0 & 0,0 \\
\hline \multirow{3}{*}{ Jenis Kelamin } & Laki-Laki & 61 & 24,2 \\
\cline { 2 - 4 } & Perempuan & 191 & 75,8 \\
\hline \multirow{3}{*}{ IMT } & Kurang & 7 & 2,8 \\
\cline { 2 - 4 } & Normal & 130 & 51,6 \\
\cline { 2 - 4 } & Lebih & 115 & 45,6 \\
\hline \multirow{3}{*}{ Pendidikan } & SD & 122 & 48,4 \\
\cline { 2 - 4 } & SMP & 63 & 25,0 \\
\cline { 2 - 4 } & SMA & 54 & 21,4 \\
\cline { 2 - 4 } & PT & 13 & 5,2 \\
\hline \multirow{3}{*}{ Sosioekonomi } & Diatas UMR & 8 & 3,2 \\
\cline { 2 - 4 } & Dibawah UMR & 241 & 95,6 \\
\cline { 2 - 4 } & Sesuai UMR & 3 & 1,2 \\
\hline
\end{tabular}


Hasil perhitungan pada tabel 1 menunjukkan bahwa dari 252 responden, sebagian besar responden berusia 60 - 74 tahun, berjenis kelamin perempuan, memiliki IMT dalam kategori normal, berpendidikan terakhir SD, dan memiliki penghasilan dibawah UMR.

Tabel 2. Distribusi self efficacy responden di wilayah kerja Puskesmas Surabaya

\begin{tabular}{|c|c|c|}
\hline Self-efficacy & Frequency & Percent \\
\hline Baik & 149 & 59,1 \\
\hline Rendah & 103 & 40,9 \\
\hline
\end{tabular}

Penilaian self-efficacy lansia menggunakan kuesioner Self Efficacy to Manage Hypertension. Hasil penilaian self-efficacy lansia hipertensi tersaji pada tabel 2. Terlihat bahwa mayoritas lansia dengan hipertensi dari jumlah total 252 lansia memiliki self efficacy dalam kategori baik

Penilaian self care behavior lansia hipertensi menggunakan kusioner H-Scale ditampilkan pada Tabel 3.

Tabel 3. Distribusi self care behavior responden di wilayah kerja Puskesmas Surabaya

\begin{tabular}{|c|c|c|}
\hline Self-care behaviour & Frequency & Percent \\
\hline Baik & 73 & 29,0 \\
\hline Cukup & 99 & 39,3 \\
\hline Kurang & 80 & 31,7 \\
\hline
\end{tabular}

Dari Tabel 3, terlihat bahwa mayoritas lansia dengan hipertensi dari jumlah total 252 memiliki self care behavior dalam kategori cukup.

Tabel 4. Analisis hubungan self efficacy dengan self care behavior

\begin{tabular}{|c|c|c|c|c|}
\hline & & & Selfefficacy & Self care behavior \\
\hline \multirow[t]{6}{*}{ Spearman's rho } & \multirow[t]{3}{*}{ Self efficacy } & Correlation Coefficient & 1,000 & $0,443^{* * *}$ \\
\hline & & Sig. (2-tailed) & . & 0,000 \\
\hline & & $n$ & 252 & 252 \\
\hline & \multirow[t]{3}{*}{ Self care behavior } & Correlation Coefficient & $0,443^{\text {** }}$ & 1,000 \\
\hline & & Sig. (2-tailed) & 0,000 & \\
\hline & & $n$ & 252 & 252 \\
\hline
\end{tabular}

Uji korelasi yang digunakan adalah Spearman Rank dengan taraf kesalahan signifikan $95 \%(\alpha=0.05$ atau 5\%). Hasil uji Spearman Rank tentang hubungan antara self-efficacy dengan self-care behavior lansia dengan hipertensi. Berdasarkan tabel 4, didapatkan nilai signifikansi adalah 0,000 dan koefisien korelasi adalah 0,443 yang artinya lansia yang memiliki self-efficacy yang baik akan cenderung untuk memiliki self-care behavior yang baik karena koefisien korelasi menunjukkan positif dan mempunyai hubungan korelasi yang sedang karena berada pada kriteria nilai 0,41-0,60.

\section{PEMBAHASAN}

Pasien dengan self efficacy yang baik akan mempunyai self care behavior yang baik. Penelitian ini menemukan pasien dengan self efficacy yang baik memiliki self care behavior yang cukup baik ${ }^{(10)}$. Penelitian ${ }^{(2)}$ menjelaskan bahwa self efficacy secara signifikan berhubungan dengan perilaku manajemen diri. Self efficacy mampu untuk memulai dan mempertahankan perubahan perilaku yang sehat saat mengatasi hambatan. Hambatan yang dirasakan oleh pasien perlu dipertimbangkan saat merancang intervensi berdasarkan self efficacy.

Prasyarat terpenting untuk perubahan perilaku adalah Self efficacy. Self efficacy mengacu pada kepercayaan seseorang dalam melakukan aktivitas tertentu, termasuk kepercayaan diri untuk melakukan aktivitas saat hambatan muncul ${ }^{(11)}$. Self efficacy menggambarkan kepercayaan tentang kemampuan diri sendiri, atau merupakan keyakinan seseorang bahwa ia dapat menguasai situasi dan menghasilkan hasil yang positif. Semakin tinggi self efficacy individu maka akan memudahkan individu memecahkan masalah dalam keadaan sulit. Individu yang meyakini bahwa dia mampu melakukan suatu perilaku tertentu akan melakukan perilaku tersebut. Sedangkan individu dengan efficacy rendah cenderung untuk tidak melakukan perilaku tersebut atau menghindarinya. Individu dengan self efficacy yang tinggi akan lebih mudah mengadopsi perilaku baru ${ }^{(10,12)}$.

Self efficacy merupakan kepercayaan diri untuk melaksanakan perilaku tertentu untuk mencapai tujuan yang spesifik. Self efficacy mempunyai 2 bagian yang mendasar yaitu self efficacy dan hasil yang diinginkan. Self efficacy mengembangkan kepercayaan diri dalam kemampuan individu untuk melakukan perilaku dan untuk mengatasi hambatan untuk mencapai tujuan tersebut. Hasil yang diinginkan adalah keyakinan seseorang bahwa mereka akan mencapai hasil kesehatan positif yang dihasilkan dari perilaku yang spesifik ${ }^{(13)}$. Self efficacy berhubungan dengan motivasi individu dan keyakinan tentang kemampuan mereka dan semua hal tersebut adalah syarat yang paling penting bagi perubahan perilaku ${ }^{(13,14)}$. Pada penelitian ini ditemukan keyakinan diri lansia dengan hipertensi dalam kategori baik. Keyakinan diri yang baik ini menyebabkan self behaviour pada lansia dengan hipertensi juga cukup baik. 
Self care behaiour dapat menjadi baik apabila lansia mempunyai self efficacy atau keyakinan diri yang baik. Lansia dengan keyakinan diri yang baik mampu menjadikan dirinya sebagai subjek yang sehat dan mandiri secara holistik di masa tuanya ${ }^{(15)}$. Self efficacy memberikan kontribusi terhadap pemahaman yang lebih baik pada lansia dalam proses perubahan perilaku kesehatan sehingga sangat penting untuk meningkatkan perawatan dirinya. Lansia hipertensi dengan self efficacy yang tinggi akan menganggap bahwa dirinya mampu menggunakan kemampuan untuk mengontrol tekanan darahnya dengan baik sesuai dengan apa yang diharapkan. Begitu pula sebaliknya, apabila lansia hipertensi dengan self efficacy yang rendah akan menganggap bahwa kemampuan yang dimiliki belum tentu dapat mengontrol tekanan darah dengan baik dan tidak mampu untuk mendapatkan hasil yang diharapkan.

\section{KESIMPULAN}

Self efficacy memiliki pengaruh yang positif terhadap self care behavior pada lansia dengan hipertensi. Semakin baik self efficacy, maka self care behavior semakin baik. Memahami dan mengkaji situasi atau kondisi lansia sangatlah penting melihat self efficacy atau keyakinan diri dari lansia terhadap penyakitnya untuk menentukan tindakan apa yang akan dilakukan untuk meningkatkan perilaku perawatan dirinya.

\section{DAFTAR PUSTAKA}

1. Zinat Motlagh SF, Chaman R, Sadeghi E, Eslami AA. Self-Care Behaviors and Related Factors in Hypertensive Patients. Iran Red Crescent Med J. 2016;18(6).

2. Manuntung A. Pengaruh Cognitive Behavioral Therapy ( CBT ) terhadap Self Efficacy dan Self Care Behavior pada Pasien Hipertensi. Mutiara Med. 2015;15(1):39-50.

3. Hu HH, Li G, Arao T. The association of family social support, depression, anxiety and self-efficacy with specific hypertension self-care behaviours in Chinese local community. J Hum Hypertens. 2015;29(3):198203.

4. Yang ZQ, Zhao Q, Jiang P, Zheng SB, Xu B. Prevalence and control of hypertension among a Community of Elderly Population in Changning District of Shanghai: A cross-sectional study. BMC Geriatr. 2017;17(1):1-9.

5. Rahmawati R, Bajorek B. Factors affecting self-reported medication adherence and hypertension knowledge: A cross-sectional study in rural villages, Yogyakarta Province, Indonesia. Chronic Illn. 2018;14(3):212-27.

6. BPS. the data of Dementia in elderly in east java. 2014; Available from: http://jatim.bps.go.id/linkTabelStatis/view/id/330

7. Lee EJ, Park E. Self-care behavior and related factors in older patients with uncontrolled hypertension. Contemp Nurse [Internet]. 2017;53(6):607-21. Available from: https://doi.org/10.1080/10376178.2017.1368401

8. Mulyati L, Yeti K, Sukamrini L. Analisis Faktor yang Memengaruhi Self Management Behaviour pada Pasien Hipertensi. J Keperawatan Padjadjaran. 2014;v1(n2):112-23.

9. Datak G, Sylvia EI, Manuntung A. Pengaruh Cognitive Behavioral Therapy Terhadap Self Efficacy dan Self Care Behavior Pasien Hipertensi di Kota Palangka Raya. J Surya Med. 2018;3(2):132-43.

10. Labata BG, Ahmed MB, Mekonen GF, Daba FB. Prevalence and predictors of self care practices among hypertensive patients at Jimma University Specialized Hospital, Southwest Ethiopia: Cross-sectional study 11 Medical and Health Sciences 1102 Cardiorespiratory Medicine and Haematology 11 Medical and . BMC Res Notes [Internet]. 2019;12(1):1-8. Available from: https://doi.org/10.1186/s13104-019-4125-3

11. Jung H, Lee JE. The impact of community-based eHealth self-management intervention among elderly living alone with hypertension. J Telemed Telecare. 2017;23(1):167-73.

12. Park E, Kim J. The Impact of a Nurse-Led Home Visitation Program on Hypertension Self-Management among Older Community-Dwelling Koreans. Public Health Nurs. 2016;33(1):42-52.

13. Putra M. et al. Application Of Health Promotion Model For Better Self-Care Behavior In Patients With Diabetes Mellitus. Belitung Nurs J [Internet]. 2019;5(6):239-45. Available from: https://belitungraya.org/BRP/index.php/bnj/index

14. Wang C, Lang J, Xuan L, Li X, Zhang L. The effect of health literacy and self-management efficacy on the health-related quality of life of hypertensive patients in a western rural area of China: A cross-sectional study. Int J Equity Health. 2017;16(1):1-11.

15. Lee JE, Han HR, Song H, Kim J, Kim KB, Ryu JP, et al. Correlates of self-care behaviors for managing hypertension among Korean Americans: A questionnaire survey. Int J Nurs Stud [Internet]. 2010;47(4):4117. Available from: http://dx.doi.org/10.1016/j.ijnurstu.2009.09.011 